\title{
OBLIGACIÓN, INCUMPLIMIENTO Y RESPONSABILIDAD CIVIL DEL MANDATARIO EN EL CÓDIGO CIVIL CHILENO*
}

\section{OBLIGATION, BREACH OF CONTRACT AND AGENTS`LIABILITY ON THE CHILEAN CIVIL CODE}

\author{
Álvaro Vidal Olivares ${ }^{* *}$ \\ María Graciela Brantt Zumarán ${ }^{* * *}$
}

\begin{abstract}
RESUMEN: La obligación del mandatario de ejecutar el encargo es típicamente una obligación de medios, cuya prestación consiste en una cierta actividad que deberá fijarse conforme a la diligencia integradora y la buena fe. La prestación así determinada difiere de la diligencia contractual propiamente tal, que consiste en la conducta a desplegar por el mandatario para asegurar la concreción de su prestación y que incide en la atribución de responsabilidad por incumplimiento. Los artículos 2158 inciso final y 2129 del Código Civil reconocen estas dos funciones de la diligencia y muestran que el régimen de responsabilidad aplicable a todo deudor de medios es el mismo que el de un deudor de resultado.
\end{abstract}

Palabras clave: Obligación, incumplimiento, responsabilidad, indemnización, mandato.

ABSTRACT: The agent's duty to perform its task is typically an obligation of means, which content consists in a certain activity that shall be determined according to integrative diligence and good faith. The obligation so determined differs from the proper contractual diligence, that is referred to the conduct to be performed by the agent in order to secure the satisfaction of its obligation and that impacts in the attribution of liability for any breach thereof. Articles 2158, last paragraph, and 2129 of the Civil Code recognize these two functions of the diligence, demonstrating that the liability's regime to be applicable to all debtors of an obligation of means is the same than the one referred to a debtor of an obligation of result.

Key words: Obligation, breach of contract, liability, damages, agency contract.

\footnotetext{
* Este artículo forma parte del proyecto Fondecyt Regular no 1120708 del investigador responsable Álvaro Vidal Olivares, y del proyecto Fondecyt Iniciación No 11100060 de la investigadora responsable María Graciela Brantt Zumarán.

** Licenciado en Ciencias Jurídicas, Pontificia Universidad Católica de Valparaíso; Doctor en Derecho por la Universidad Autónoma de Madrid; Profesor titular de derecho civil de la Facultad de Derecho de la Pontificia Universidad Católica de Valparaíso. Dirección postal: Facultad de Derecho Pontificia Universidad Católica de Valparaíso, Avenida Brasil 2950, Valparaíso, Chile. Correo electrónico: alvaro.vidal@ucv.cl

*** Licenciada en Ciencias Jurídicas, Pontificia Universidad Católica de Valparaíso; Doctora en Derecho por la Pontificia Universidad Católica de Valparaíso; profesora asociada de derecho civil de la Facultad de Derecho de la Pontificia Universidad Católica de Valparaíso. Dirección postal: Facultad de Derecho Pontificia Universidad Católica de Valparaíso, Avenida Brasil 2950, Valparaíso, Chile. Correo electrónico: maria.brantt@ucv.cl
} 


\section{ASPECTOS PREVIOS}

La doctrina nacional se encuentra dividida sobre un tópico de la responsabilidad civil contractual, a saber, el rol de la diligencia exigible al deudor según la obligación sea de medios o resultado y, por ende, las condiciones de procedencia de la indemnización de daños por incumplimiento de una u otra clase de obligación.

Por una parte, dentro de lo que podría denominarse una línea objetivadora de la responsabilidad civil contractual, algunos autores reservan la diligencia para las obligaciones de medios, al punto de afirmar que en ellas la culpa es un elemento constitutivo del incumplimiento, siendo impertinente hablar, en esta clase de obligaciones, de un incumplimiento objetivo. La culpa y el incumplimiento se confunden. Al mismo tiempo, descartan la presencia y cualquier injerencia de la diligencia y la culpa en las obligaciones de resultado; en ellas solo interesaría el opus, de modo que su sola no consecución produciría el incumplimiento del deudor, quedando sometido a la obligación de indemnizar ${ }^{1}$. Este sector de la doctrina aísla la norma del artículo 1547 del Código Civil para las obligaciones de medios. En apoyo de esta tesis objetiva se recurre al artículo 1556 del Código Civil, que prescribe la indemnización de daños por el solo hecho del incumplimiento prescindiendo de la culpa del deudor. De lo anterior se sigue que en las obligaciones de medios la culpa, o el incumplimiento, que se identifican, se presumirían a partir de la regla del inciso tercero del artículo 1547 del Código Civil, debiendo el deudor acreditar que fue diligente o, lo que es igual, que cumplió. Si no lo hace queda sujeto a responsabilidad, a menos que alegue y pruebe la intervención de un caso fortuito sinónimo de una imposibilidad absoluta construida exclusivamente a partir de la causalidad, al margen de toda valoración de la conducta del deudor frente al hecho externo y sus consecuencias. Dos serían los regímenes de responsabilidad civil por incumplimiento, el subjetivo con culpa presunta para las obligaciones de medios y el objetivo para las de resultado ${ }^{2}$.

\footnotetext{
1 Esta línea está representada especialmente por el profesor Carlos Pizarro, quien precisamente se ha pronunciado reiteradamente descartando el carácter objetivo del incumplimiento en las obligaciones de medios, afirmando que en ellas la culpa es un elemento constitutivo del incumplimiento. Según expresa: "en presencia de obligaciones contractuales de diligencia no es posible diferenciar el cumplimiento de la diligencia debida, o lo que es lo mismo, el incumplimiento de la culpa". Asimismo, ha rechazado que la diligencia despliegue función alguna en las obligaciones de resultado, por cuanto en su opinión en ellas solo es relevante si la obligación fue satisfecha o no, "excluyéndose un análisis del comportamiento del deudor destinado a lograr la satisfacción de la prestación”. Pizarro (2008) p. 263. Reitera tal idea para las obligaciones de resultado, reconociendo que aunque puede ser necesaria una diligencia promotora, no hay efectos asociados a la misma. Pizarro (2010) pp. 590-591. Para este planteamiento es la presencia o ausencia del opus comprometido lo que excluye o determina el incumplimiento, y con ello la responsabilidad. En esta misma corriente se ubica en nuestro derecho la profesora Domínguez, quien afirma que en las obligaciones de resultado no se discute acerca de la ausencia de culpa porque en ellas la culpa es irrelevante, Domínguez (2010) p. 36-37. En igual sentido se ha pronunciado, Rodríguez (2008), Incumplimiento pp. 414-415, y Rodríguez (2008) p. 471.

2 Cabe destacar que este planteamiento, sostenido en nuestro país por los autores mencionados, ha sido también afirmado en el derecho francés especialmente por Larroumet (1996) pp. 610 y ss; y Larroumet (2007) pp. 294 y ss. Y en el derecho español por YzQuierdo (2001) pp. 126 y ss. También en Argentina Picasso destaca que se ha afirmado la doctrina según la cual en las obligaciones de resultado se está frente a un factor objetivo de atribución, Picasso (2008) p. 165.
} 
Por otra, estamos quienes, siendo fieles a la letra de nuestro Código Civil y a su tradición, entendemos que la diligencia exigible constituye un elemento de la naturaleza de cualquier clase de obligación, sea de medios o de resultado, y que su consideración interesa solo para el caso de incumplimiento, de configuración objetiva, y que resulta útil para dar respuesta acerca de si el deudor responde, o no, ante su acreedor ${ }^{3}$. La particularidad de las obligaciones de medios refiere a la manera en que se define el contenido de su prestación, que normalmente las partes no describen en el contrato ${ }^{4}$, tal contenido lo integra el juez recurriendo a una lex artis o bien a las reglas de conducta de común observancia por un operador medio del tráfico en el lugar del deudor. Se habla de una función integradora de la diligencia para aludir a la regla que operará para la fijación de la conducta debida por el deudor y que constituye el objeto de la prestación. En esta tarea integradora cabe un papel esencial al principio de la buena fe objetiva, que sirve de fundamento de los distintos contenidos de conducta de la prestación no explicitados por las partes al contratar. La buena fe del artículo 1546 del Código Civil actúa como regla de interpretación integradora ${ }^{5}$. Tal función de la diligencia da respuesta al "hacer debido" por el deudor y se sitúa en el plano de la obligación y, seguidamente, de su cumplimiento o incumplimiento ${ }^{6}$. Es una regla de integración más que una de conducta, no obstante que de su aplicación resulte la definición del objeto ideal del contrato, que es aquello que debe ejecutar el deudor para dar por satisfecha la prestación y el interés del acreedor.

Sí constituye una regla de conducta propiamente tal, distinguible de la prestación objeto de la obligación, sea de medios o de resultado, la diligencia exigible al deudor, constitutiva de un elemento de la naturaleza del contrato, y que tiene por finalidad promover la concreción o realización de la prestación debida, al imponerle al deudor la necesidad de prever e impedir la intervención de obstáculos o impedimentos que puedan afectar la realización de la prestación -definida sea por las partes o por la integración judicial-y/o superar sus consecuencias, esto es, cumplir a pesar de tal intervención. Esta es la genuina diligencia contractual -la llamada promotora del cumplimiento- que, por regla general, sirve de título de imputación de responsabilidad, o para resolver sobre la exoneración por caso fortuito, lo que presupone valorar la conducta del deudor concreto. Resulta difícil diferenciar la función promotora de la diligencia -regla de conducta anexa a la prestación misma- de su función de título de imputación de responsabilidad ${ }^{7}$.

\footnotetext{
3 En este sentido nos hemos pronunciado previamente en: Vidal (2010) p. 581; Brantt (2010) pp. 206 y ss.; VidAl y BRANTt (2012).

4 En España, Díez Picazo destaca esta característica de las obligaciones de medios cuando, refiriéndose a la llamada función de integración de la prestación debida que se asigna a la diligencia, expresa que ella sirve para dotar de contenido y determinar una prestación, generalmente de hacer, identificada por la partes con una referencia de carácter genérico, y agrega luego que, tratándose de servicios profesionales, generalmente las partes se limitan a aludir genéricamente al tipo de servicios. DíEz-Picazo (2008) p. 121-122.

5 En tal sentido: López (2010) p. 358 y 440; Vidal (2000) p. 216.

6 Díez Picazo destaca este aspecto cuando expresa que tratándose de las obligaciones de medios o de diligencia, la violación de la regla de la diligencia, que es el contenido de la prestación, determina el incumplimiento de mismo. Díez-Picazo (2008) p. 745. En sentido similar: Badosa (1987) pp. 168; Brantt (2012) Vidal (2010) pp. 579-580.
}

7 En tal sentido: Badosa (1987) pp. 215 y ss; Vidal (2010) p. 581 y ss. 
Así, la distinción entre obligaciones de medios y de resultado incide en la configuración de la prestación, pero no en las reglas de la indemnización de daños, comunes a cualquier obligación en que incida el incumplimiento ${ }^{8}$.

Cabe consignar que este debate se ha producido ya en términos abstractos, sin referencia a ninguna obligación o tipo contractual concreto, ya con ocasión de dos sentencias de la Corte Suprema que más que recoger la clasificación de obligaciones de medios y de resultado, y las consecuencias que de ella pudieran seguirse, se han pronunciado sobre la norma del artículo 1698 del Código Civil y su relación con la del inciso tercero del artículo 1547 del mismo cuerpo legal, en lo que respecta a la carga de la prueba del incumplimiento y la culpa?

Por lo anterior, estimamos que resulta de especial interés examinar la diligencia en sus funciones arriba anunciadas en un tipo contractual que naturalmente produce obligaciones de hacer de medios, como es el contrato de mandato -regulado en el Código Civil en el Título XXIX del Libro IV- más aun considerando el pronunciamiento de la Corte Suprema en su sentencia de 8 de abril de 2010, rol 2248 - 2008, que si bien reconoce que la diligencia cumple una función promotora del cumplimiento, identifica con ella ciertas conductas debidas por el mandatario situadas más bien en el ámbito de la prestación que de aquella actividad tendiente a impulsar el cumplimiento. No obstante la crítica que se desliza, la sentencia permitirá, con apoyo del régimen legal del mandato, demostrar que pese a que las obligaciones nacidas para el mandatario sean naturalmente de medios, no queda excluida la diligencia contractual propiamente tal -impulsora del cumplimiento- y que es característica de toda especie de obligación. Se incardinarán las disposiciones de los artículos 1547, 2129 y 2158, todos del Código Civil.

El presente trabajo se divide en dos secciones. La primera tiene por objeto la definición de la prestación a que se obliga el mandatario, la regla de cumplimiento e incumplimiento, y la de responsabilidad por daños. Y, la segunda, el análisis crítico de la sentencia de la Corte Suprema citada. Finaliza con un cuerpo de conclusiones.

\section{PRESTACIÓN, CUMPLIMIENTO E INCUMPLIMIENTO, Y RESPONSABILIDAD DEL MANDATARIO}

\subsection{Prestación, Cumplimiento e incumplimiento}

La extensa regulación que el Código Civil da al contrato de mandato representa el régimen legal supletorio o dispositivo de este tipo contractual, que las partes pueden disponer o modificar con cierta libertad, aunque en la práctica el contrato normalmente se limita

\footnotetext{
8 Vidal y Brantt (2012) pp. 279 y ss.; Vidal (2010) p. 581.

9 Las sentencia de la Corte Suprema que han sido objeto de análisis a este respecto corresponden a la de 10 de diciembre de 2008, rol 1771/2007, referida a una demanda de responsabilidad contractual interpuesta con ocasión de un contrato para la reparación de un motor empleado en el funcionamiento de una planta de ácidos, en que la discusión precisamente se centró en la carga de la prueba del incumplimiento por los desperfectos que presentó el motor luego de sucesivas reparaciones; y la de 7 de septiembre de 2010, rol 1089-2009, a propósito del incumplimiento de la obligación de cuidado que recae sobre el establecimiento educacional respecto de sus estudiantes en virtud del contrato de educación, con ocasión de una gira de estudios, en que el debate también se refirió a lo referido a la carga de la prueba del incumplimiento de ese deber de cuidado. En doctrina, analizando las sentencias referidas, se encuentra: Vidal (2010); Pizarro (2010); Tapia (2010); Vidal y Brantt (2012).
} 
al encargo que hace el mandante y la aceptación tácita (ejecución del encargo) por parte del mandatario. Tal práctica es el reflejo de la norma sobre el perfeccionamiento del contrato, la del artículo 2124 del Código Civil, incluso en los casos en que es solemne, por cuanto la solemnidad refiere al encargo no así al contrato.

Quien fija el contenido del mandato es el mandante, al confiar la gestión de uno o más negocios al mandatario, describiendo aquel o aquellos y definiendo, con más o menos extensión, las facultades de que dispondrá el mandatario. Empero, el mandante nada dice acerca del cumplimiento y/o incumplimiento de las partes, particularmente del mandatario. Por tal razón, cobra especial relieve el régimen legal, no solo el particular aludido, sino también el general del Código Civil sobre los efectos de las obligaciones, particularmente aquellas disposiciones que refieren a las obligaciones de hacer.

Nos ocuparemos de la situación del mandatario en el cumplimiento de sus obligaciones, y de la del mandante afectado por el incumplimiento del primero ${ }^{10}$. El punto de partida es la respuesta a la siguiente interrogante: ¿a qué se obliga el mandatario?, o, lo que es lo mismo: ¿a qué tiene derecho el mandante en virtud del contrato?

Nos situamos en el ámbito de las obligaciones de hacer, que en el caso del mandato naturalmente son de medios o de actividad y que, por tanto, como sucede con esta clase de obligaciones, tienen por objeto una prestación que se traduce en el despliegue de una cierta actividad del deudor dirigida a proporcionar un interés, objeto o resultado al acreedor, pero sin que dicho interés, objeto o resultado integre la prestación misma, no están in obligatione ${ }^{11}$. Tratándose de la obligación del mandatario de ejecutar el encargo, el carácter de medios se aprecia en que su prestación no comprende el éxito del negocio encomendado, sino la actividad del mandatario orientada a dicho fin, pero sin garantizar al mandante la obtención de los beneficios esperados con la gestión. En el caso resuelto por la Corte Suprema a que nos referiremos en la segunda sección -mandato para la contratación de un seguro de desgravamen en un crédito hipotecario-, la actividad comprometida por el mandatario se orienta, en último término, al pago por la aseguradora de la indemnización en caso de muerte del mandante, sin llegar a garantizarlo. La obtención del pago no depende exclusivamente de la actividad del deudor, sino también de otros factores ajenos a la misma que pueden impedirla. La satisfacción del mandante pende de la actividad que realice el mandatario encaminada al opus mencionado, no por su consecución.

En esta clase de obligaciones la buena fe del artículo 1546 actúa como regla de interpretación integradora de la prestación, confiriendo al mandante el derecho a confiar en que el mandatario ejecutará aquella actividad que emplearía un operador razonable en sus

10 Principalmente, el derecho a la indemnización de daños que el incumplimiento del mandatario irrogue al mandante, sin perjuicio de considerar la excepción de contrato no cumplido que le reconoce el inciso final del artículo 2158 del Código Civil.

11 Así se expresa, refiriéndose a las obligaciones de medios, Peñailillo (2003) p. 223. Por su parte, Cabanillas describe las obligaciones de medios afirmando que en las obligaciones de actividad -como él las denomina- "el deudor está obligado a desarrollar a favor del acreedor una determinada conducta, encaminada a alcanzar el resultado esperado por el acreedor, que satisface su interés primario (v. gr. la curación, la victoria en el juicio, etcétera). Sin embargo, debido al carácter aleatorio o incierto de dicho resultado, el deudor no garantiza su obtención, y cumple si actuó con la diligencia para alcanzarlo”. Cabanillas (1993) p. 9. 
mismas circunstancias, en ocasiones - como ocurre con los profesionales- referida a una lex artis $^{12}$; en otras, al buen sentido de un hombre medio; orientada, en todo caso, a la realización de un fin que es el querido por el acreedor. Se llena de contenido la prestación, fijando la actividad debida por el mandatario, el objeto ideal del contrato ${ }^{13}$. Como se ha explicado, normalmente el mandante nada expresa sobre la actividad o actividades específicas que debe realizar el mandatario para cumplir su encargo, y la forma como debe hacerlo; o lo que es lo mismo: omite la indicación de los términos concretos del encargo y a los que conforme al artículo 2131 del Código Civil, el mandatario debe ceñirse rigorosamente. Tales términos contribuyen a dibujar el aludido objeto ideal y, por tanto, inciden en la determinación del cumplimiento o incumplimiento del mandatario. Incluso, tratándose de mandatos de simple administración o generales, aun cuando el legislador enumera a vía ejemplar en el artículo 2132 algunos actos que se definen a partir del giro administrativo ordinario del mandante; y sin perjuicio de que tal giro ordinario difiere en cada caso, igualmente persiste el problema en lo que concierne a la actividad debida por el mandatario y la forma de ejecutarla. En tal hipótesis, el juez a partir de la consideración del giro ordinario -no definido por el legislador, sino por las circunstancias del propio mandante- y el objeto de mandato igualmente integrará el aludido objeto ideal para así resolver el caso en cuestión.

Alegado que sea el incumplimiento que causa la insatisfacción del mandante, el juez definirá los términos del mandato y, en tal tarea, resultará esencial considerar la naturaleza del objeto del encargo, y las particulares circunstancias del mandatario. En efecto, se requiere el conflicto entre el mandante y el mandatario, en el que el primero alega que el encargo no fue ejecutado correctamente, causándole un perjuicio.

Surge entonces la siguiente interrogante: ¿qué normas del Código Civil colaboran al juez en esta tarea? El citado artículo 2131 dispone que el mandatario se ceñirá rigorosamente a los términos del mandato, precepto que es una concreción del principio de la identidad del pago del artículo 1569 del Código Civil, principio que el mismo título XXIX atempera al prever excepciones que autorizan al mandatario, bajo ciertas circunstancias, para alejarse de los términos del encargo ${ }^{14}$. De la lectura conjunta de ambas disposiciones resulta que el mandatario debe ejecutar el negocio conforme a los términos del encargo, debiendo ceñirse estrictamente a ellos, de modo tal que el mandante no está obligado a

\footnotetext{
$12 \mathrm{Al}$ respecto, Díez Picazo afirma que tratándose de servicios profesionales, la actividad que debe desplegar el deudor es el modelo de diligencia profesional, que es todo lo que exija la lex artis, que define como "el conjunto de específicos reglamentos de la profesión y todo aquello que en la profesión ordinariamente se realiza”, DíEzPicAzo (2008) p. 122.

13 Cfr. Oyaneder (2004). El autor, examinando el rol de la buena fe como fuente de deberes de conducta en materia contractual, destaca que ella contribuye a dar fisonomía a la actividad a desplegar por los sujetos de la relación jurídica, imponiendo conductas que se agregan a las previstas por las partes y a las establecidas por la ley ante el silencio de aquellas. Agrega que la buena fe integra la estructura de la conducta comprometida. Si bien lo plantea en términos generales, no referido exclusivamente a las obligaciones de medios, ciertamente se trata de un rol de la buena fe que destaca de manera especial en dicha clase de obligaciones, por la habitual indefinición o falta de determinación precisa de la prestación que las caracteriza, de modo que en la fijación de lo exigido al deudor como debido, la buena fe se manifiesta contribuyendo a dar contenido a la diligencia integradora.

14 Como sucede, por ejemplo, con las disposiciones de los artículos 2134, 2147, 2148, 2149 del Código Civil. Así lo reconoce Stitchinin (2008) pp. 275 y ss.
} 
aceptar un cumplimiento diverso, sea en su forma o contenido. Cobra aquí interés otra disposición, la del inciso final del artículo 2158, que impide al mandante negarse al cumplimiento de sus propias obligaciones a menos que pruebe la culpa del mandatario. Lo que hace el mandante, a la luz de este precepto, es alegar la ejecución imperfecta del encargo y en ella justifica su negativa de cumplimiento de sus propias obligaciones. Si así se entiende, la referencia a la culpa debe entenderse hecha al incumplimiento del mandatario en tanto no ha ejecutado el encargo conforme al contrato ex artículo 2331 del Código Civil. Contrariamente, el artículo 2129 del Código Civil emplea la expresión culpa en su sentido propio, el de los artículos 44 y 1547 del mismo cuerpo legal. De este modo, puede afirmarse que, habiéndose ejecutado el encargo, el mandante solo puede oponerse a cumplir con sus obligaciones, alegando y probando el cumplimiento imperfecto del mandatario ${ }^{15}$. El legislador impone al acreedor la prueba del cumplimiento imperfecto desde que habiéndose establecido la ejecución del encargo por el mandatario, el acreedor no lo acepta, alegando que si bien lo ejecutó lo hizo imperfectamente, recayendo en él la prueba del defecto o desviación en el cumplimiento ${ }^{16}$. Así, siguiendo a Stitchkin, si el mandato tiene por objeto la venta de un inmueble y el mandatario prueba haber llevado a cabo el negocio y entrega el precio al mandante, este podría alegar que no lo hizo correctamente desde que convino una comisión innecesaria o bien una excesiva ${ }^{17}$. Tal regla es la prevista en el inciso final del artículo 2158 y que está en plena armonía con el artículo 1698 del Código Civil. Lo que alega el acreedor es la subsistencia de la obligación pese a haber mediado y estar acreditado el cumplimiento formal del deudor.

Estas dos disposiciones -la del artículo 2131 y la del artículo 2158- son claves para la comprensión del fenómeno del cumplimiento e incumplimiento del mandatario y de los efectos de este último. De ellas se infiere que tal incumplimiento no refiere a la consecución del resultado que interesaba al mandante al hacer el encargo -el éxito o menor costo del negocio o los negocios- sino a la no conformidad de su actividad respecto de los términos del encargo; quedando en evidencia que el mandatario normalmente contrae una obligación de medios $^{18}$. El artículo 2158 es la única norma en el Código Civil que permitiría

15 Como expresa Stitchkin, refiriéndose a esta regla del inciso final del artículo 2158: "La norma parte del supuesto que el negocio se ha realizado totalmente, pues de otro modo no es posible que el mandante alegue que no ha tenido buen éxito o que ha podido desempeñarse a menor costo. Si ya se discute el éxito obtenido o los gastos en que ha incurrido el mandatario, es porque el negocio se ha realizado (...)" STItchkin (2008) p. 393. Con ello pone de manifiesto que lo alegado por el mandante en estos casos es una ejecución defectuosa del encargo por el mandatario, un cumplimiento imperfecto. El mandatario ejecutó el encargo, pero sin conformarse a los términos del mismo, y ello es lo que alega el mandante para negarse a cumplir con sus propias obligaciones.

16 Al respecto, conviene destacar lo afirmado por Díez Picazo en el sentido que cuando el deudor de un obligación de medios infringe la diligencia que da contenido a la prestación y por tanto incumple, es el acreedor quien deberá probar la culpabilidad del deudor entendida como la inobservancia de las reglas que integran su prestación. DíEz-Picazo (2008) p. 745. En definitiva, el autor destaca que en tal caso el acreedor deberá probar el incumplimiento, lo que coincide con la regla de nuestro artículo 2128 inciso final.

17 Así lo plantea Stitchkin (2008) p. 394.

18 En este sentido, Díez Picazo, refiriéndose a la obligación del mandatario, afirma que el mandato lo compromete no a la obtención de un resultado, sino únicamente al despliegue de una actividad de gestión, y que por ello resulta fundamental la diligencia exigible. Díez-PiCAzo (2008) p. 720. En sentido similar se pronuncia Meza Barros cuando afirma que el mandatario no se obliga a llevar al éxito el negocio que se la ha confiado sino 
afirmar un reconocimiento, aunque implícito, de las obligaciones de medios, desde que el mandatario no garantizaría el éxito o menor costo de la gestión, sino solo el empleo de una correcta actividad según lo ordene la lex artis o el buen sentido de un operador medio en su lugar. Solo así se explica que un resultado negativo o desfavorable para el mandante no sea suficiente para afirmar el incumplimiento del mandatario, sino que se requiere que este último no hubiere conformado su actividad a los términos del mandato, siendo esta la causa, y no otra, de dicho resultado desfavorable. En definitiva, ninguna de las dos disposiciones refiere a la atribución de responsabilidad u obligación de indemnización, sino a una de sus condiciones, el incumplimiento.

\subsection{RESPONSABILIDAD}

Acreditado que sea el incumplimiento del mandatario - no hizo lo que debía en la gestión del o los negocios encomendados-, aquel se entiende imputable por aplicación de los artículos 2129 y 1547 del Código Civil, y dará lugar a responsabilidad, a menos que el deudor acredite, según esta última disposición, un caso fortuito que le sirva de excusa de su incumplimiento.

Concurriendo la condición del incumplimiento del mandatario, la diligencia contractual del citado artículo 1547 despliega su función promotora, ya sea, como título de imputación de responsabilidad, ya sea para justificar la concurrencia de los requisitos del caso fortuito como causa de exoneración ${ }^{19}$. Cabe preguntarse: ¿en qué se materializa tal diligencia? El mandatario, como todo deudor, junto con la ejecución de la prestación -en este caso la gestión de uno o más negocios- se obliga a actuar de modo de prevenir, impedir, resistir y superar los eventuales obstáculos o impedimentos que puedan sobrevenir con posterioridad a la celebración del contrato, y que puedan afectar el normal desenvolvimiento y ejecución de la prestación. Ella refiere a una actividad ajena y adicional al objeto del encargo -a la prestación- no obstante que favorece y se dirige a su consecución; esa es su finalidad ${ }^{20}$. De esta manera, de sobrevenir un impedimento, el mandatario debe actuar

\footnotetext{
a poner lo que esté de su parte para conseguir tal resultado. Meza (1999) p. 381. Sin decirlo expresamente, el autor se pronuncia en el sentido de que el mandatario no compromete al mandante un resultado sino cierta actividad, lo que permite calificar su obligación como una de medios. En igual sentido se expresa Cabanillas, quien afirma que "el mandatario solo garantiza su actividad diligente y no la realización y buen fin del encargo que le ha encomendado el mandante”, Cabanillas (1993) p. 117.

19 Respecto de este punto, cabe considerar lo afirmado por Díez Picazo, quien al dar cuenta de las funciones de la diligencia en las relaciones obligatorias, alude a la llamada función promotora de la diligencia, y destaca que es muy difícil separarla de la función de definición de un título de imputación de la responsabilidad cuando esta se funde en la negligencia. Díez-Picazo (2008) p. 122.

20 Describiendo esta función de la diligencia, Badosa expresa que ella se caracteriza por ser extrínseca a la actividad debida, y por tener un carácter instrumental respecto de la misma. Agrega que para que la prestación pase de ser un proyecto a una conducta materialmente existente, el cumplimiento, es necesaria otra actividad, cuyo único fin sea impulsar su realización. Tal actividad la denomina diligencia en función promotora del cumplimiento. Badosa (1987): p. 175. Por su parte, Díez Picazo expresa que tiene por objeto la actividad necesaria para impulsar la prestación debida, dando lugar a deberes de conservación de la prestación preparada para cumplir y de previsión de los sucesos que puedan afectar el programa de la obligación, que puedan poner en riesgo su conservación. Díez-Picazo (2008) p. 271. Por su parte Peñailillo afirma que esta función de la diligencia "conduce a ejecutar (permite o hace factible) la prestación comprometida", Peñallillo (2009) p. 498. A su vez,
} 
en orden a superarlo en sí, o en sus consecuencias, cumpliendo igualmente su obligación. Es esta diligencia la que permite, a partir de las condiciones del caso fortuito, exonerar o atribuir responsabilidad al mandatario. De este modo, solo en la medida en que habiéndose desplegado tal diligencia no se haya podido evitar o superar el incumplimiento, el hecho que se invoque como tal podrá, atendida la diligencia exigible al deudor, ser calificado de imprevisible e irresistible y, así, exonerar al deudor. De lo contrario, la falta de esta diligencia, traducida en que el hecho invocado era previsible, o no siéndolo, era resistible en sí o en sus consecuencias, atribuirá responsabilidad al deudor sujetándole a la obligación de indemnizar. En este sentido debe entenderse la culpa de los artículos 2129 y 1547, que actúa como título de imputación de responsabilidad y que difiere del incumplimiento -falta de aquella actividad debida- y a que hace alusión el inciso final del artículo 2158. Es posible diferenciar claramente el incumplimiento de la culpa como criterio de atribución, esta supone la omisión de la diligencia propiamente tal, aquella promotora o impulsora de la ejecución de la prestación ${ }^{21}$.

Entonces, esta diligencia contractual consiste en una actividad o actuación del deudor y no en una simple actitud o disposición sicológica suya favorable hacia el cumplimiento. Es una diligencia en un sentido objetivo, que se mide a partir de la conducta debida por el deudor y aquella efectivamente realizada por él. Es una regla de conducta, pero no integrante de la prestación misma, y por ello su realización no se traduce propiamente en cumplimiento, sino que tiene un fin específico: asegurar el cumplimiento. Es un "hacer" más allá de la prestación para resguardar su concreción y ulterior satisfacción del acreedor. De allí que se manifieste especialmente en conductas de previsión y resistencia o superación ante los obstáculos al cumplimiento. El deudor debe anticiparse a ellos para evitarlos, y si no es posible, debe actuar despejándolos, al menos en sus efectos, para impedir que ellos afecten el cumplimiento y si el incumplimiento igualmente tiene lugar, deberá superar las consecuencias de tales obstáculos cumpliendo, aunque sea tardíamente. La fuente de estos deberes de conducta que aglutina la diligencia promotora es el propio contrato y como se ha explicado, aquella es un elemento de la naturaleza de este según el artículo 1547 del Código Civil. Mientras subsista la obligación contractual el deudor debe actuar a objeto de cumplirla, incluso cuando logre acreditar un caso fortuito y cesen sus consecuencias ${ }^{22}$.

Baraona afirma que ella alude a una "actuación básica para cumplir la prestación que se traduce en comportamientos determinados" y a la que es posible llamar "diligencia promotora del cumplimiento. Su función material es dar lugar el cumplimiento”, Baraona (1997) p. 166.

21 Cabe a este respecto tener en cuenta lo afirmado por Díez Picazo en torno a cuándo la responsabilidad del deudor quedará fundada en la culpa, expresando que ello sucederá cuando se presente una infracción del deudor a la regla de lo que Badosa denomina diligencia promotora, "entendida como el deber de esfuerzo a que está sometido el deudor para conservar la posibilidad de que la prestación sea cumplida y para remover los obstáculos o impedimentos que a tal posibilidad puedan oponerse”, Dítz-Picazo (2008) p. 746. Con ello el autor reconoce la incidencia de esta diligencia en la definición de lo que el deudor debe hacer frente a los eventuales obstáculos al cumplimiento, y cuya ausencia u omisión puede conducir a la responsabilidad.

22 En este sentido, BrantT (2011) p. 744. Fueyo se expresaba en sentido similar, vinculando la diligencia exigible al deudor con aquella conducta de resistencia a los eventos impeditivos del cumplimiento: "La resistencia del deudor al nacimiento y efectos del evento que atenta contra el debido cumplimiento, es variable según la obligación de que se trate, pues sabemos que el grado de diligencia que debe prestar el deudor depende de lo que disponga al respecto la ley en cada caso" Fueyo (2004) p. 404. Al respecto cabe citar también lo afirmado 
El mandatario debe probar que el incumplimiento se debió a un hecho imprevisible e irresistible, todo lo cual se define según esta diligencia, que en materia de mandato se somete a una regla particular, desde que si bien el mandatario responde, conforme al artículo 2129, de la culpa leve, ella queda sujeta a apreciación en términos más o menos estrictos según si el mandato ha sido remunerado, o si el mandatario manifestó repugnancia al mismo y se vio en cierto modo forzado a aceptar el mandato a instancias del mandante. Cabe aquí preguntarse si esta regla excluye la general del artículo 1547, desde que no es extraño en la práctica que el contrato de mandato ceda exclusivamente en beneficio de una de las partes, el mandante o el mandatario. De aplicarse esta última disposición, si el mandato cede exclusivamente en beneficio del mandante, el mandatario se haría cargo de la culpa grave, y en caso contrario, de la culpa levísima. Si aceptamos esta tesis, el juez tendría una mayor latitud para valorar la conducta del mandatario ante la presencia de un obstáculo o impedimento, y así resolver acerca de la posible exoneración alegada por este último ${ }^{23}$. En el caso de la sentencia de la Corte Suprema no hay duda que el mandato cede principalmente en beneficio del mandatario quien fija unilateralmente los términos del encargo.

En síntesis, pese al tenor del artículo 2158 inciso final del Código Civil, la responsabilidad civil contractual por incumplimiento del mandatario queda sujeta a las mismas condiciones que aquella del derecho común y opera de igual manera. Es decir, probado o establecido que sea el incumplimiento, este atribuye responsabilidad al deudor debido a que se entiende que la causa de tal inejecución era previsible o, no siéndolo, era resistible en sí o en sus consecuencias. Tal regla solo cede en la medida que el deudor, el mandatario, acredite la concurrencia de los elementos del caso fortuito, exonerándose de la obligación de indemnizar. Así resulta de la lectura conjunta de los artículos 2129 y 1547 del Código Civil $^{24}$. La regla del artículo 2158 inciso final refiere al incumplimiento, no a la culpa como factor de imputación de responsabilidad. Por consiguiente, el régimen de responsabilidad por incumplimiento es el mismo independiente de que se trate de una obligación de medios -como es el caso del mandatario- o de resultado 25 .

por los Mazeaud, en el sentido de que resistir supone cumplir pese a dicho acontecimiento (la fuerza mayor) Mazeaud et al. (1962) p. 321.

23 Afirmando que en todo caso el mandatario responde de la culpa leve, siendo el artículo 2129 una clara excepción a la regla del artículo 1547 del Código civil, y sosteniendo que la apreciación más o menos estricta solo puede incidir en la definición de los daños a reparar, se pronuncia Claro Solar (1910) pp. 274-275. También se pronuncia categóricamente en el sentido de que el artículo 2129 altera la regla del artículo 1547 STITCHKIN (2008) p. 387.

24 También Claro Solar se expresa en el sentido de que tal regla general es la aplicable a la responsabilidad del mandatario. Claro Solar (1910) p. 268.

25 Negando la existencia de un diferente régimen de responsabilidad según se trate de obligaciones de medios o de resultado, en España, Jordano Fraga afirma que en las obligaciones de medios debe distinguirse adecuadamente el terreno del incumplimiento material -que viene dado en ellas por la circunstancia de que el deudor no se ha ajustado a la diligencia debida- del juicio de responsabilidad, lo que a su vez permitirá resolver lo referido a la responsabilidad en el sentido de entender que en dicho ámbito existen unas mismas reglas, con un mismo límite para toda clase de obligaciones. Jordano (1991) pp. 56-57. También se pronuncia afirmando un régimen de responsabilidad unitario independientemente del tipo de obligación. Morales (2010) pp. 30 y ss. Asimismo, sin afirmarlo de manera explícita, parece ubicarse en tal línea Díez Picazo, cuando señala que en las obligaciones de medios una vez que se ha acreditado el incumplimiento del deudor por no haber observado las reglas de diligencia que 
En contribución a lo explicado, el artículo 2150 del Código Civil reconoce expresamente la idea que envuelve la diligencia promotora, al imponer al mandatario la obligación de ejecutar el encargo a pesar de verse afectado por un caso fortuito que haga imposible su ejecución con arreglo a las instrucciones del mandante. En efecto, según la disposición, si ello ocurre, la primera regla es la de liberar al mandatario del encargo, sin necesidad de constituirse en agente oficioso, debiendo tomar las providencias conservativas que las circunstancias exijan. Ella se justifica porque hay imposibilidad sobrevenida no imputable al deudor que extingue la obligación. Sin embargo, si no es posible dejar de obrar sin comprometer gravemente al mandante, la misma disposición ordena que el mandatario debe tomar el partido que más se acerque a las instrucciones del mandante y que más convenga al negocio. En otros términos, se impone al mandatario una actividad no prevista originalmente, y que debe realizar tanto para evitar un perjuicio al mandante como para que este alcance la satisfacción de su interés. Es decir, en definitiva, el mandatario queda obligado igualmente a ejecutar el encargo, aunque apartándose de las instrucciones del mandante que no le es posible cumplir. La disposición reitera la regla sobre la prueba del caso fortuito, imponiéndosela al deudor, tal como lo hacen las normas de los artículos 1547 y 1674. Si se examina el supuesto que prevé el precepto, se advierte que el mandatario incurre en un incumplimiento -apartarse de las instrucciones dadas por el mandante- por haber acaecido un caso fortuito cuyas condiciones deberá acreditar, y a pesar de tal circunstancia, como en rigor sigue igualmente obligado, debe proseguir con la ejecución del encargo con una suerte de cumplimiento sustituto igualmente idóneo para el interés del acreedor, el mandante ${ }^{26}$. Si así lo hace, se le libera de la obligación de indemnizar pese a que objetiva-

integran su prestación, subsiste para este la carga de probar la existencia de un hecho impeditivo de la aplicación de dichas reglas. Y rechaza la jurisprudencia que en España se ha pronunciado en el sentido de que si se producen daños con la actuación del deudor en estos casos, se presumiría no solo la culpa sino el cumplimiento defectuoso, lo que a su juicio no permite resolver el problema de las causas ignotas, lo que sí se logra si se parte de la regla general conforme a la cual el deudor para exonerarse tiene que probar un hecho extraño que impidió la prestación, de modo que en un supuesto de causas ignotas, conforme a dicha regla su responsabilidad no quedaría excluida. DíEz-PicAzo (2008) p. 745-746. Por su parte Villanueva Lupión se pronuncia categóricamente desechando un diferente régimen de responsabilidad para obligaciones de medios y de resultado, afirmando que "no existe un régimen de responsabilidad dual en función de la distinción entre las obligaciones de medios y de resultado". Agrega que el Código Civil español establece de manera general la presunción de negligencia, para ambos tipos de obligaciones y destaca que la raíz de la disfunción de esta pretendida responsabilidad dual radica en el error de confundir la inejecución del contrato y el juicio de responsabilidad, Villanueva (2009) pp. 365 y ss. En Francia se han pronunciado en sentido similar: Le Tourneau (2004) p. 100 y ss. Por nuestra parte, nos hemos ya expresado en esta línea en Vidal (2010); Brantt (2010); Vidal y Brantt (2012).

26 Al respecto, conviene destacar que en el régimen de la Convención de Viena, modelo central de la nueva construcción del sistema de responsabilidad por incumplimiento contractual, la idea de exoneración del deudor está construida sobre la base de los impedimentos ajenos a su esfera de control y razonablemente imprevisibles al contratar e insuperables en sí y sus consecuencias. Tal exoneración se debe configurar en un contexto en que el deudor, y concretamente del vendedor, garantiza al acreedor la satisfacción de su interés, lo que comprende incluso la necesidad de acudir al mercado en busca de un sustituto comercialmente razonable del objeto del contrato cuando un obstáculo ajeno a su esfera de control e imprevisible al contratar le impide cumplir con el originalmente debido, y ello es así porque en definitiva el deudor debe actuar razonablemente para superar el obstáculo al cumplimiento o sus consecuencias. Se trata de una exigencia que encuentra su origen en el Common Law y que en nuestro derecho cabe sostener a la luz de la regla de conducta de la diligencia exigible. Sobre este punto: VIDAL (2010) pp. 346 y ss. 
mente hubo incumplimiento. La actuación impuesta por la norma al mandatario, de actuar del modo más cercano a las instrucciones y que más convenga al negocio, es una actividad exigida por la diligencia: frente al obstáculo que le impide seguir las instrucciones del mandante, debe actuar de modo de sobreponerse e intentar llevar a cabo el encargo lo más cercanamente posible a como lo dispuso el mandante.

En síntesis, hemos precisado que en el mandato la prestación se configura a partir de la interpretación integradora que hace el juez por aplicación del artículo 1546 del Código Civil recurriendo a la lex artis relevante o al buen sentido de un operador medio en el lugar del mandatario; que tratándose de una obligación de medios, si el acreedor -el mandanteno se conforma con el cumplimiento del mandatario en tanto entiende que este no se ha ajustado a los términos del mandato, deberá acreditarlo y si así ocurre, el mandatario será responsable por los daños que hubiere irrogado al mandante, salvo que pruebe la concurrencia de las condiciones del caso fortuito, las que se definen caso a caso según la diligencia exigible de acuerdo a las disposiciones de los artículos 2129 y 1547, ambas del Código Civil. Se distingue claramente, la configuración de la prestación de medios, su incumplimiento y la responsabilidad del mandatario.

\section{ANÁLISIS DE LA SENTENCIA DE LA CORTE SUPREMA ¿DILIGENCIA PROMOTORA O CONTENIDO DE LA PRESTACIÓN?}

Los hechos sobre los que se pronuncia la Corte Suprema son los que siguen. El causante de los demandantes contrató con el banco demandado un mutuo hipotecario. En una de las cláusulas de dicho contrato se facultaba al banco para contratar un seguro de desgravamen hipotecario por todo el tiempo de vigencia de la deuda y por un monto equivalente a ella. El banco contrató el referido seguro y los cobros se hicieron conjuntamente con los dividendos durante todos los meses hasta el fallecimiento del mutuario, momento en que cesaron los pagos. Producida la muerte del mutuario, el banco denunció el siniestro a la compañía de seguros y esta rechazo el pago fundándose en la omisión por parte del deudor en la declaración de salud de ciertos antecedentes vinculados con la causa de su muerte. Pese a lo anterior, el banco no informó a los herederos sobre el rechazo del siniestro y, por ende, de la negativa del pago de la indemnización.

Fuera de lo anterior, el banco tampoco impugnó el rechazo ni realizó gestión alguna en orden a requerir de la compañía de seguros una mayor y fundada justificación, conformándose con la negativa inicial. Además, retuvo las primas que le fueron devueltas por la aseguradora, y como si fuera poco, posteriormente demandó a la sucesión el pago del saldo insoluto de la deuda.

Atendidos los hechos descritos, los herederos del mutuario interponen demanda en contra del banco, reclamando la indemnización de daños y perjuicios causados por el incumplimiento del contrato de mandato existente entre este y el causante. El banco se defiende al contestar la demanda, alegando que no existía mandato con el causante y, por ende, mal podría imputársele responsabilidad por su incumplimiento.

El Tribunal de primera instancia rechazó la demanda en todas sus partes argumentando que no hubo contrato de mandato entre el causante de los demandantes y el banco 
demandado, y la existencia de una cláusula de exoneración de responsabilidad para el evento de no contratación o no renovación del seguro.

La Corte de Apelaciones de Valdivia confirmó la sentencia de primera instancia y los demandantes interponen en contra de su fallo un recurso de casación en el fondo, fundado en la infracción de los artículos 2116, 2124 y 2129 del Código Civil y el artículo 170 No 4 del Código de Procedimiento Civil. El recurso sostiene la infracción del artículo 2116 del Código Civil desde que se desconoce la existencia del mandato contenido en la cláusula duodécima del contrato de mutuo hipotecario, cláusula que expresamente confería un encargo al banco y que este además ejecutó; asumiendo, por lo tanto, todas las obligaciones propias de dicho contrato. También, se asevera la vulneración del artículo 2124 del Código Civil toda vez que el mandato se habría perfeccionado por la aceptación tácita del encargo por el banco al proceder a la contratación del seguro a nombre del causante; y del artículo 2129 del mismo cuerpo legal, atendido que este indiscutiblemente consagra que todo mandatario debe actuar con la debida diligencia y cuidado que emplea en sus negocios propios y que responde de la culpa leve en la ejecución del encargo.

Respecto de la vulneración de los artículos 2116 y 2124, la Corte Suprema sostuvo la existencia efectiva de un contrato de mandato, desde que el banco aceptó la gestión, haciéndose cargo de la contratación del seguro por cuenta y riesgo del causante, cargando las respectivas primas en los dividendos mensuales hasta el fallecimiento del deudor, lo que a juicio del máximo Tribunal muestra que se produjo un evidente error de derecho por los jueces de instancia, al calificar erróneamente la referida cláusula del contrato, infringiéndose el artículo 2116 del Código Civil.

En relación con la vulneración del artículo 2129 del Código Civil, la Corte Suprema se pronuncia acerca del incumplimiento y la responsabilidad del banco, para cuyo efecto primeramente se detiene en la configuración de la prestación a que se obligó el deudor por virtud del mandato que da por establecido. Así, sostiene que el deudor, junto con obligarse a hacer, debe emplear en la ejecución de la prestación una diligencia promotora que se materializa en la adopción de medidas concretas para la superación de los obstáculos o impedimentos que afectan el fiel desarrollo de la prestación (considerando octavo).

Seguidamente, destaca el carácter de contrato de confianza del mandato, vinculándolo con el principio de la buena fe objetiva del artículo 1546 del Código Civil, como regla integradora del contenido de la prestación. Se lee en la sentencia: "que acorde con el artículo 2116, al emplear el legislador la palabra confía está dando al mandato el carácter de contrato de confianza, inspirado en la fe que el mandante tiene en el mandatario, lo que necesariamente hace llegar a la conclusión que la buena fe es realmente un elemento intrínseco del contrato, dando fisonomía a la actividad a desplegar por los sujetos de la relación jurídica, en este caso, o sea en lo que interesa, por el mandatario" (considerando décimo). Según el parecer del máximo Tribunal, un mínimo de lealtad y buena fe le imponía al banco demandado, frente al rechazo del siniestro por parte de la aseguradora, el deber, en cumplimiento de su mandato, de dar a conocer a la sucesión del causante el acontecimiento referido, a efecto de darle la posibilidad de llevar a cabo las acciones que estimare, y no acreditó que lo haya hecho, impidiendo así la correspondiente defensa o descargos de esa sucesión. Agrega, además, que el banco se conformó con la sola manifestación de la asegu- 
radora en orden a que desestimaba el pago del seguro, sin requerir la demostración de los motivos de tal rechazo, que consistían en la preexistencia de una enfermedad no declarada por el causante. El banco no justificó la realización de acto alguno tendiente a lograr el pago del seguro ante la aseguradora, habiendo, por el contrario, ocultado la información del caso a la sucesión, demandándola posteriormente en forma directa, y dejando incluso en su poder las primas que le fueron devueltas por la aseguradora.

Finaliza su razonamiento expresando que lo expuesto claramente revela que el banco demandado no fue diligente en el cumplimiento de las obligaciones que, en su calidad de mandatario tenía, en lo tocante al mandato materia de esta causa. Concluye que los jueces del grado, al resolver como lo hicieron, no solo infringieron el artículo 2116 del Código Civil, sino también el artículo 2129, al soslayar que el mandatario responde hasta de la culpa leve en el cumplimiento de su encargo (considerando undécimo).

En virtud de lo expresado, se acoge el recurso de casación en el fondo, dándose lugar a la acción indemnizatoria por incumplimiento de la obligación del banco demandado.

No obstante coincidir con la decisión de la Corte Suprema que acoge el recurso casando la sentencia, por existir un contrato de mandato e incumplimiento del mismo y condenando al banco a la correspondiente indemnización de daños; no concordamos con el razonamiento de la sentencia, desde que confunde la regla de fijación del contenido de la prestación con la diligencia promotora que reconoce le es exigible al mandatario.

En efecto, el primer argumento de la Corte Suprema para sostener el incumplimiento y responsabilidad del banco, es el reconocimiento de que toda obligación de hacer envuelve una diligencia promotora del cumplimiento. Sin embargo, si se considera lo expresado en la sección que precede, las conductas que el sentenciador define como exigibles para el mandatario en razón de tal diligencia -dar aviso a los herederos del rechazo del siniestro, exigir justificación a la compañía de seguros, e insistir ante esta para lograr el pago- integran más bien el "hacer", objeto de la obligación, y corresponden a lo que en doctrina se califica como diligencia en función integradora o configuradora de la prestación en las obligaciones de medios. De este modo, la no realización de las conductas que el juez integra, aplicando la buena fe objetiva, a la prestación, son constitutivas de incumplimiento y no de culpa como título de imputación de responsabilidad. En efecto, como se precisa en la primera parte de este trabajo, técnicamente debemos diferenciar la prestación en sí misma y su inejecución, de la responsabilidad por omisión de la tantas veces aludida diligencia promotora. Como se ha expresado no se comparte la tesis de la culpa como elemento constitutivo del incumplimiento en las obligaciones de medios.

Por ende, una cuestión distinta es que, acreditado el incumplimiento del mandatario -omisión de la prestación o defecto en su ejecución-, este solo hecho le atribuya responsabilidad mientras él no acredite el caso fortuito que, como se ha expresado, se define conforme a la diligencia promotora que le es exigible al deudor. Las conductas que define la Corte Suprema son intrínsecas a la prestación, forman parte de ella y su omisión constituye incumplimiento en los términos de los artículos 2131, 2158 inciso final y 1569 del Código civil.

Con el objeto de ilustrar sobre la distinción entre prestación debida y diligencia promotora en el contrato de mandato, podríamos plantearnos el siguiente supuesto: el banco incumple el contrato al omitir dar oportuna noticia a los herederos acerca del rechazo del 
siniestro. En tal caso, cabría sin embargo la posibilidad de que el mandatario intente exonerarse de la indemnización alegando que su omisión obedece a una causa ajena, imprevisible e irresistible para él ex artículo 45 del Código Civil, atendida la diligencia que le impone el artículo 2129 del mismo código; por ejemplo, por la paralización de la empresa de correos o la interrupción de las comunicaciones a causa de un terremoto. Sea o no el hecho alegado constitutivo de un caso fortuito, es claro que frente a este al banco podría haberle sido exigible preverlo y resistirlo en sí, o en sus consecuencias. Si la causa del incumplimiento hubiera sido la interrupción de las comunicaciones por un terremoto, como el banco estaba obligado a informar, igualmente debe cumplir su obligación una vez reanudadas aquellas, requiriendo a la aseguradora respuesta a su denuncia e informando a los herederos, para así observar rigorosamente los términos del mandato, aunque tardíamente. Si se mantiene en inactividad y transcurren los plazos para impugnar la decisión de la aseguradora, habrá incumplimiento imputable por la falta de la diligencia promotora. Aquí, el impedimento u obstáculo era resistible no obstante su carácter de imprevisible.

No obstante la confusión conceptual de la Corte Suprema y aclarada esta, sí debemos destacar que el Tribunal acierta al hacerse cargo, como primera cuestión, de la definición del contenido de la obligación, reconociendo que pese a que la cláusula contractual no lo define, es el juez el que, aplicando la buena fe del artículo 1546 del Código Civil, debe llenar el vacío contractual precisando las gestiones o actuaciones que el banco debiera haber realizado de haberse comportado como otro operador diligente en su lugar. De este modo, el Tribunal concluye que el banco no debió conformarse con la negativa de la aseguradora, sino que debió exigir la justificación del fundamento del rechazo y, al mismo tiempo, dar noticia de tal acontecimiento a la sucesión a objeto de que esta hubiere quedado en condición de reclamar ante la aseguradora.

La actividad objeto del mandato y a la que está obligado el mandatario no se agota en la sucinta descripción de la cláusula del contrato que se limita a conferirle facultades para la contratación y renovación del seguro por el monto del crédito y por todo el período del servicio de la deuda, sino que va más allá, extendiéndose a otras gestiones a que también estaba obligado el mandante. El juez es quien da fisonomía al contenido prestacional, que no alcanza eso sí el resultado deseado por el mandante, esto es, el pago de la indemnización, opus que está fuera de la obligación. Así de hecho lo reconoce el fallo de primera instancia, al expresar que aún entendiendo que el banco estuviere obligado, tal obligación es una de medios y no de resultado, y por cuenta y riesgo del deudor, por lo que si la compañía se niega a pagar el seguro de desgravamen, ello no hace responsable al banco demandado (considerando decimotercero). De lo que se sigue que sí habría incumplimiento y responsabilidad si el banco no hubiera empleado los medios que le eran exigibles y fuese esta la causa del no pago de la indemnización por la aseguradora. Y, en efecto, la Corte Suprema, precisamente, entiende que el banco no hizo lo que debía o lo que habría hecho un operador razonable frente al rechazo al pago de la indemnización, y en base a este incumplimiento contractual le condena a la indemnización de daños a favor de la sucesión demandante.

Seguidamente, cuando el sentenciador en su considerando undécimo afirma que la conducta del banco demandado revela claramente que no fue diligente en el cumplimiento 
de las obligaciones que como mandatario tenía, debió afirmarse más bien que tal comportamiento constituía incumplimiento del demandado -ex artículo 2158 inciso final- que le impone la obligación de indemnizar conforme el artículo 2129 del Código Civil, a menos que se hubiere alegado y probado el caso fortuito, lo que en el caso de autos no acontece.

\section{CONCLUSIONES}

La obligación de ejecutar el encargo que recae sobre el mandatario es una obligación típicamente de medios, cuyo contenido, al no estar normalmente determinado por el mandante, deberá fijarlo el juez, considerando las circunstancias del caso, integrando el contenido de la prestación cobrando realce la llamada diligencia integradora, diferenciada de la promotora del cumplimiento que es la genuina diligencia contractual a la que refiere nuestro Código Civil, especialmente en el artículo 1547.

Así, el carácter de medios de la obligación del mandatario no excluye la presencia de la diligencia contractual propiamente dicha o promotora, que el deudor debe poner en ejecución para asegurar e impulsar el cumplimiento, de modo que su empleo incidirá en responsabilidad o eventual exoneración.

El régimen legal del mandato reconoce ambos roles de la diligencia: el configurador del contenido de la prestación en el artículo 2158 inciso final y el de actividad de preservación de la posibilidad de cumplir en el artículo 2129, que muestra que el régimen de responsabilidad del mandatario, como la de todo deudor de medios, es el mismo aplicable a las obligaciones de resultado.

En la sentencia comentada, aparece claramente que en el mandato incorporado al contrato de mutuo hipotecario se le confieren al banco mandatario facultades limitadas, sin embargo, el juez lo integra a partir de lo que era razonable esperar de un operador del tráfico profesional en la posición del banco, ensanchando el contenido obligacional, imputándole responsabilidad por la infracción de tal contenido. Lo anterior, con independencia de la crítica sobre el recurso a la denominada diligencia promotora para explicar dicha integración, en circunstancias que debió referirse a la llamada diligencia integradora o en función de integración.

A partir del caso y el análisis que de él se hace en este trabajo, se desprende la distinción entre ambas funciones de la diligencia respecto de la definición del objeto ideal del contrato -función integradora- y de la atribución de responsabilidad por omisión de aquella actividad promotora del cumplimiento

Finalmente, la sentencia nos permite demostrar que el legislador en el artículo 2158 tuvo en mente la noción de obligaciones de medios, por lo que cuando se expresa en términos de "culpa" alude al cumplimiento imperfecto del mandatario cuya prueba recae en el acreedor que lo alega, el mandante.

\section{BIBLIOGRAFÍA CITADA}

Badosa, Ferrán (1987): La diligencia y la culpa del deudor en la obligación civil (Real Colegio de España, Bolonia) 1042 pp. 
BARAONA, Jorge (1997): "Responsabilidad contractual y factores de imputación de daños: apuntes para una relectura en clave objetiva", Revista Chilena de Derecho 24 número 1: pp. 151-177.

BrantT, María Graciela (2010): El caso fortuito y su incidencia en el derecho de la responsabilidad civil contractual. Concepto y alcance del caso fortuito en el Código Civil chileno (Abeledo Perrot, Santiago) 239 pp.

Brantt, María Graciela (2011): La irresistibilidad en el caso fortuito y el deber de actuación del deudor como condición para su exoneración en Estudios de derecho civil VI (Abeledo Perrot, Santiago) pp. 737-749.

BrantT, María Graciela (2012): "La prueba del cumplimiento imperfecto en las obligaciones de medios y de resultado", en Estudios de derecho civil VII (Abeledo Perrot, Santiago) pp. 495-510.

Cabanillas, Antonio (1993): Las obligaciones de actividad y de resultado (Bosch Editor, Barcelona) $201 \mathrm{pp}$.

Claro Solar, Luis (1910): "Ligeras observaciones sobre la prestación de la culpa en el contrato de mandato", Revista de Derecho y Jurisprudencia y Gaceta de los Tribunales, número 1, tomo 7: pp. 255-275.

Díez-Picazo, Luis (2008): Fundamentos del Derecho Civil Patrimonial II: Las relaciones obligatorias (Thomson Civitas, Madrid) $1092 \mathrm{pp}$.

Domínguez, Carmen (2010): "El problema de la culpa presunta contractual y las obligaciones de medio y resultado: sus implicancias para la responsabilidad médica”, en Cuadernos de Análisis Jurídico. Colección de Derecho Privado número 6 (Fundación Fueyo, Santiago) pp. 21-44.

Fueyo Laneri, Fernando (2004): Cumplimiento e incumplimiento de las obligaciones (Editorial Jurídica, Santiago) 650 pp.

Jordano Fraga, Francisco (1991): “Obligaciones de medios y de resultados (a propósito de una jurisprudencia reciente”, en Anuario de Derecho Civil volumen 44 número 1 pp. 5-96.

Larroumet, Christian (1996): Droit Civil, III: Les obligations. Le contrat (Económica, París).

Larroumet, Christian (2007): "La causa extraña", en Mantilla, Fabricio; Ternera, Francisco (edit.), Contratos en el derecho privado (Legis, Bogotá) pp. 293-317.

Le Tourneau, Philippe (2004): La responsabilidad civil (Legis, Bogotá) 204 pp.

López, Jorge (2010): Los contratos. Parte general (Abeledo Perrot, Santiago) 577 pp.

Mazeaud, Henri; Mazeaud, León; Mazeaud, Jean (1962): Lecciones de derecho civil tomo II (Jurídicas Europa-América, Buenos Aires).

Meza Barros, Ramón (1999): Manual de derecho civil. De las fuentes de las obligaciones tomo I (Editorial Jurídica, Santiago) 442 pp.

Morales Moreno, Antonio (2010): Incumplimiento del contrato y lucro cesante (Civitas, Madrid) $192 \mathrm{pp}$.

Oyaneder, Patricio (2004): "Comportamiento contractual de buena fe ¿Impone la buena fe deberes de conducta?” en Actualidad Jurídica número 10: pp. 287-291.

Peñailillo, Daniel (2003): Obligaciones: teoría general y clasificaciones. La resolución por incumplimiento (Editorial Jurídica, Santiago) 502 pp. 
Peñailillo, Daniel (2009): "Responsabilidad contractual objetiva", en Estudios de derecho civil IV (LegalPublishing, Santiago) pp. 487-502.

Picasso, Sebastián (2008): "Algunos aspectos de la responsabilidad civil de los médicos en el derecho argentino", en Cuadernos de Análisis Jurídico. Colección de Derecho Privado número 4 (Fundación Fueyo, Santiago) pp. 155-171.

Pizarro, Carlos (2008): "La culpa como elemento constitutivo del incumplimiento en las obligaciones de medio o de diligencia”, en Revista de Derecho de la Pontificia Universidad Católica de Valparaíso número 31: pp. 255-265.

Pizarro, Carlos (2010): "Diligencia, incumplimiento y exoneración de responsabilidad". Comentario a sentencia Corte Suprema No ingreso 1.771-2007, en Estudios de Derecho Civil V (Santiago, Abeledo Perrot, 2009) pp. 587-593.

Rodríguez Pinto, María Sara (2008): “Incumplimiento y exoneración de responsabilidad en los contratos de prestación de servicios. Los lineamientos de la responsabilidad estricta del proveedor", en Estudios de Derecho Civil III (Santiago, LegalPublishing), pp. 503-517.

Rodríguez Pinto, María Sara (2008): "La responsabilidad civil del proveedor en los contratos de prestación de servicios”, en Guzmán, Alejandro (edit.), Colección de Estudios de Derecho Civil en homenaje a la Profesora Inés Pardo De Carvallo (Valparaíso, 2008).

Stitchkin, David (2008): El mandato civil (Editorial Jurídica, Santiago) 534 pp.

TAPIA, Mauricio (2010): "Incumplimiento contractual y obligaciones de garantía", en Estudios de Derecho Civil V (Abeledo Perrot, Santiago), pp. 595-602.

VIDAL, Álvaro (2000): "La construcción de la regla contractual en el derecho civil de los contratos", en Revista de Derecho de la Universidad Católica de Valparaíso, número 21: pp. 209-227.

VIDAL, Álvaro (2010): "Incumplimiento y atribución de responsabilidad en las obligaciones de medio y de resultado (a propósito de una sentencia de la Corte Suprema No ingreso 1771-2008”, en Estudios de Derecho Civil V (Abeledo Perrot, Santiago) pp. 569-585.

VIDAL, Álvaro (2010): "Atribución y exoneración de responsabilidad en la compraventa internacional. Construcción de las reglas a partir del artículo 79 de la Convención de Viena”, en Pizarro, Carlos; Vidal, Álvaro (Edits.), Incumplimiento contractual, resolución e indemnización de daños (Universidad del Rosario, Bogotá) pp. 313-351.

Vidal, Álvaro y BrantT, María Graciela (2012): “Cumplimiento e incumplimiento y responsabilidad del deudor en el Código civil. A propósito de la sentencia de la Corte Suprema de 7 de septiembre de 2010" en Revista de Derecho Universidad Católica del Norte año 19 número 1: pp. 271-291.

Villanueva Lupión, Carmen (2009): El servicio como objeto de tráfico jurídico (La ley, Madrid) $600 \mathrm{pp}$.

Yzquierdo Tolsada, Mariano (2001): Sistema de responsabilidad civil, contractual y extracontractual (Reus, Madrid) 286 pp.

\section{NORMAS CITADAS}

Código Civil. 


\section{JURISPRUDENCIA CITADA}

ACE Seguros S.A con FCAB Ingeniería y Servicios Ltda. (2008): Corte Suprema, 10 de diciembre de 2008, disponible en: http://www.poderjudicial.cl/juris_pjud/jurisprudencia2.php (última consulta: 24 septiembre 2012).

Netz Puschmann con The Wessex School (2010): Corte Suprema, 8 de abril de 2010, disponible en http://www.poderjudicial.cl/juris_pjud/jurisprudencia2.php (última consulta: 24 septiembre 2012).

Pizarro con Banco del Estado de Chile (2010): Corte Suprema, de 7 de septiembre de 2010, disponible en: http://www.poderjudicial.cl/juris_pjud/jurisprudencia2.php (última consulta: 24 septiembre 2012). 
